Annals of Pure and Applied Mathematics

Vol. 18, No. 1, 2018, 73-78

ISSN: 2279-087X (P), 2279-0888(online)

Published on 20 August 2018

Annals of

www.researchmathsci.org

DOI: http://dx.doi.org/10.22457/apam.v18n1a10

Pure and Applied

Mathematics

\title{
On Reduced Zagreb Indices of Polycyclic Aromatic Hydrocarbons and Benzenoid Systems
}

\author{
V.R.Kulli \\ Department of Mathematics \\ Gulbarga University, Gulbarga 585106, India \\ e-mail: vrkulli@gmail.com
}

Received 8 July 2018; accepted 15 August 2018

Abstract. In this paper, we introduce the reduced modified first Zagreb index, reduced inverse degree index, reduced zeroth-order Randić index, reduced F-index and generalized reduced first Zagreb index of a graph. Also we determine these indices for polycyclic aromatic hydrocarbons and jagged rectangle benzenoid systems.

Keywords: reduced Zagreb indices, polycyclic aromatic hydrocarbon, benzenoid system

AMS Mathematics Subject Classification (2010): 05C05, 05C07, 05 C90

\section{Introduction}

Let $\mathrm{G}$ be a finite, simple connected graph with vertex set $V(G)$ and edge set $E(G)$. The degree $d_{G}(v)$ of a vertex $v$ is the number of vertices adjacent to $v$. We refer to [1] for undefined term and notation.

Chemical graph theory is a branch of Mathematical Chemistry which has an important effect on the development of Chemical Sciences. Several topological indices have been considered in Theoretical chemistry. defined as

Recently, Furtula et al., in [2] introduced the reduced second Zagreb index,

$$
R M_{2}(G)=\sum_{u v E(G)}\left(d_{G}(u)-1\right)\left(d_{G}(v)-1\right) .
$$

Recently, some new reduced indices were studied, for example, in $[3,4,5,6,7]$.

The reduced first Zagreb index [8] of a graph $G$ is defined as

$$
R M_{1}(G)=\sum_{u \in V(G)}\left(d_{G}(u)-1\right)^{2} .
$$

Motivated by the definition of the reduced first Zagreb index, we introduce the reduced modified first Zagreb index, reduced inverse degree index, reduced zeroth-order Randić index, induced F-index and generalized reduced first Zagreb index as follows:

The reduced modified first Zagreb index of a graph $G$ is defined as

$$
{ }^{m} R M_{1}(G)=\sum_{u \in V(G)} \frac{1}{\left(d_{G}(u)-1\right)^{2}} .
$$




\section{V.R.Kulli}

The reduced inverse degree index of a graph $G$ is defined as

$$
R I D(G)=\sum_{u \in V(G)} \frac{1}{d_{G}(u)-1} .
$$

The reduced zeroth-order index of a graph $G$ is defined as

$$
R Z(G)=\sum_{u \in V(G)} \frac{1}{\sqrt{d_{G}(u)-1}} .
$$

The reduced F-index of a graph $G$ is defined as

$$
R F(G)=\sum_{u \in V(G)}\left(d_{G}(u)-1\right)^{3} \text {. }
$$

The generalized reduced first Zagreb index of a graph $G$ is defined as

$$
R M_{1}^{a}(G)=\sum_{u \in V(G)}\left(d_{G}(u)-1\right)^{a} .
$$

where $a$ is a real number.

Recently, many topological indices were studied, for example, in $[9,10$, $11,12,13,14,15,16,17,18,19,20,21,22,23]$; the modified first Zagreb index was studied in $[24,25]$ and the F-index was studied in [26,27,28,29,30,31].

In this paper, some reduced Zagreb indices of polycyclic aromatic hydrocarbons and benezenoid systems are computed. For more information about polycyclic aromatic hydrocarbons and benzenoid systems see [32].

\section{Results for polycyclic aromatic hydrocarbons}

In this section, we focus on the chemical graph structure of the family of polycyclic aromatic hydrocarbons, denoted by $P A H_{n}$. The first three members of the family $P A H_{n}$ are given in Figure 1.

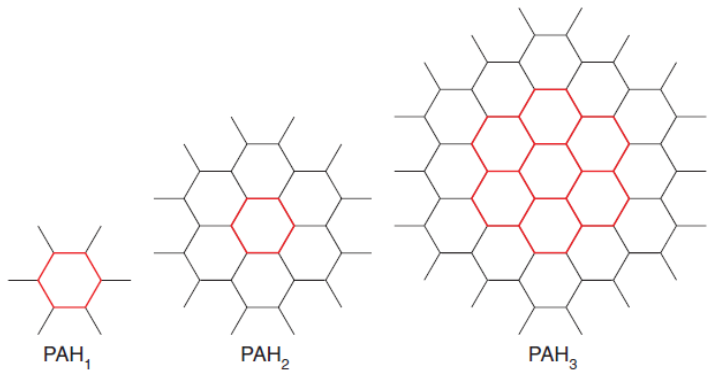

Figure 1:

Let $G=P A H_{n}$ be the chemical graph in the family of polycyclic aromatic hydrocarbons. By calculation, we obtain that $G$ has $6 n^{2}+6 n$ vertices. In $G$, there are two types of vertices as follows:

$$
\begin{array}{ll}
V_{1}=\left\{u \in V(G) \mid d_{G}(u)=1\right\}, & \left|V_{1}\right|=6 n . \\
V_{3}=\left\{u \in V(G) \mid d_{G}(u)=3\right\}, & \left|V_{3}\right|=6 n^{2} .
\end{array}
$$
of $\mathrm{PAH}_{n}$.

In the following theorem, we compute the generalized reduced first Zagreb index 
On Reduced Zagreb Indices of Polycyclic Aromatic Hydrocarbons and Benzenoid Systems

Theorem 1. The generalized reduced first Zagreb index of the family of polycyclic aromatic hydrocarbons $P A H_{n}$ is

$$
R M_{1}^{a}\left(P A H_{n}\right)=2^{a} \times 6 n^{2} .
$$

Proof: Let $G=P A H_{n}$ be the chemical graph in the family of polycyclic aromatic hydrocarbons. From equation (6) and by cardinalities of the vertex partition of $P A H_{n}$, we have

$$
\begin{aligned}
R M_{1}^{a}\left(P A H_{n}\right) & =\sum_{u \in V(G)}\left(d_{G}(u)-1\right)^{a} . \\
& =(1-1)^{a} 6 n+(3-1)^{a} 6 n^{2} \\
& =2^{a} \times 6 n^{2} .
\end{aligned}
$$

We obtain the following results by using Theorem 1 .

Corollary 1.1. The reduced first Zagreb index of $P A H_{n}$ is given by

$$
R M_{1}\left(P A H_{n}\right)=24 n^{2} \text {. }
$$

Proof: Put $a=2$ in equation (7), we get the desired result.

Corollary 1.2. The reduced modified first Zagreb index of $P A H_{n}$ is given by

$$
{ }^{m} R M_{1}\left(P A H_{n}\right)=\frac{3}{2} n^{2} .
$$

Proof: Put $a=-2$ in equation (7), we get the desired result.

Corollary 1.3. The reduced inverse degree index of $P A H_{n}$ is given by

$$
\operatorname{RID}\left(P A H_{n}\right)=3 n^{2} \text {. }
$$

Proof: Put $a=-1$ in equation (7), we obtain the desired result.

Corollary 1.4. The reduced zeroth-order Randić index of $P A H_{n}$ is given by

$$
R Z\left(P A H_{n}\right)=\frac{6}{\sqrt{2}} n^{2} .
$$

Proof: Put $a=-\frac{1}{2}$ in equation (7), we obtain the desired result.

Corollary 1.5. The reduced F-index of $P A H_{n}$ is given by

$$
R F(G)=48 n^{2} \text {. }
$$

Proof: Put $a=3$ in equation (7), we get the desired result.

\section{Results for benzenoid systems}

In this section, we focus on the chemical graph structure of a jagged rectangle benzenoid system, denoted by $B_{m, n}$ for all $m, n \in N$. Three chemical graphs of a jagged rectangle benzenoid system are presented in Figure 2. 
V.R.Kulli

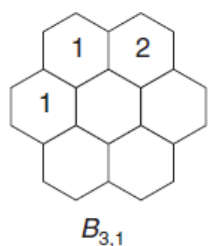

$B_{3,1}$

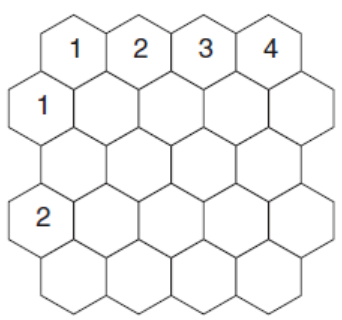

$B_{5,2}$

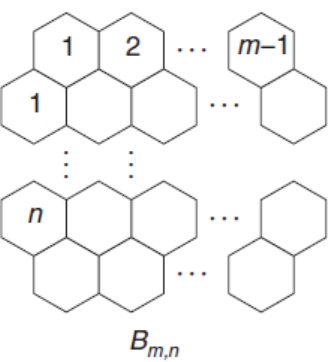

Figure 2:

Let $G=B_{m, n}$ be the chemical graph in the family of a jagged rectangle benzenoid system. By calculation, we obtain that $G$ has $4 m n+4 m+2 n-2$ vertices. In $G$, there are three types of vertices as follows:

$$
\begin{aligned}
& V_{2}=\left\{u \in V(G) \mid d_{G}(u)=2\right\}, \quad\left|V_{2}\right|=2 m+4 n+2 . \\
& V_{3}=\left\{u \in V(G) \mid d_{G}(u)=3\right\}, \quad\left|V_{3}\right|=4 m n+2 m-2 n-4 \text {. }
\end{aligned}
$$
of $B_{m, n}$.

In the following theorem, we compute the generalized reduced first Zagreb index

Theorem 2. Let $B_{m, n}$ be the family of a jagged rectangle benzenoid system. Then

$$
R M_{1}^{a}\left(B_{m, n}\right)=(2 m+4 n+2)+2^{a}(4 m n+2 m-2 n-4) .
$$

Proof: Let $G=B_{m, n}$ be the chemical graph in the family of a jagged rectangle benzenoid system. From equation (6) and by cardinalities of the vertex partition of $B_{m, n}$, we have

$$
\begin{aligned}
R M_{1}^{a}\left(B_{m, n}\right)= & \sum_{u \in V(G)}\left(d_{G}(u)-1\right)^{a} \\
& =(2-1)^{a}(2 m+4 n+2)+(3-1)^{a}(4 m n+2 m-4 n-4) \\
& =(2 m+4 n+2)+2^{a}(4 m n+2 m-4 n-4)
\end{aligned}
$$

We obtain the following results by using Theorem 2 .

Corollary 2.1. The reduced first Zagreb index of $B_{m, n}$ is given by

$$
R M_{1}\left(B_{m, n}\right)=16 m n+10 m-4 n-14 .
$$

Proof: Put $a=2$ in equation (8), we get the desired result.

Corollary 2.2. The reduced modified first Zagreb index of $B_{m, n}$ is given by

$$
{ }^{m} R M_{1}\left(B_{m, n}\right)=m n+\frac{5}{2} m-\frac{7}{2} n+1 .
$$

Proof: Put $a=-2$ in equation (8), we get the desired result.

Corollary 2.3. The reduced inverse degree index of $B_{m, n}$ is given by

$$
R I D\left(B_{m, n}\right)=2 m n+3 m+2 n \text {. }
$$

Proof: Put $a=-1$ in equation (8), we get the desired result. 
On Reduced Zagreb Indices of Polycyclic Aromatic Hydrocarbons and Benzenoid Systems

Corollary 2.4. The reduced zeroth-order Randić index of $B_{m, n}$ is given by

$$
R Z\left(B_{m, n}\right)=2 \sqrt{2} m n+(2+\sqrt{2}) m+(4-\sqrt{2}) n+(2-\sqrt{2}) .
$$

Proof: Put $a=-\frac{1}{2}$ in equation (8), we obtain the desired result.

Corollary 1.5. The reduced F-index of $B_{m, n}$ is given by

$$
R F\left(B_{m, n}\right)=32 m n+18 m-12 n-30 \text {. }
$$

Proof: Put $a=3$ in equation (8), we get the desired result.

Acknowledgement. The author is thankful to the referee for his/her suggestions.

\section{REFERENCES}

1. V.R.Kulli, College Graph Theory, Vishwa International Publications, Gulbarga, India (2012).

2. B.Furtula, I.Gutman and S.Ediz, On difference of Zagreb indices, Discrete Appl. Math., 178 (2018) 83-88.

3. I.Gutman, B.Furtula and C.Elphick, Three new/old vertex degree based topological indices, MATCH Commun. Math. Comput. Chem., 72 (2014) 617-682.

4. B.Horoldagva, L.Buyantoglokh and S.Dorjsembe, Difference of Zagreb indices and reduced second Zagreb index of cyclic graphs with cut edges, MATCH Commun. Math. Comput. Chem., 78 (2017) 337-350.

5. V.R.Kulli, Reduced second hyper-Zagreb index and its polynomial of certain silicate networks, Journal of Mathematics and Informatics, (2018).

6. V.R.Kulli, General reduced second Zagreb index of certain networks, submitted.

7. V.R.Kulli, Some multiplicative reduced indices of certain nanostructures, submitted.

8. S.Ediz, On the reduced first Zagreb index of graphs, Pacific Journal of Applied Mathematics, 8(2) (2016) 99-102.

9. V.R.Kulli, On $K$ indices of graphs, International Journal of Fuzzy Mathematical Archive, 10(2) (2016) 105-109.

10. V.R.Kulli, On $K$-edge index of some nanostructures, Journal of Computer and Mathematical Sciences, 7(7) (2016) 373-378.

11. V.R.Kulli, On $K$ Banhatti indices and $K$ hyper-Banhatti indices of $V$-Phenylenic nanotubes and nanotorus, Journal of Computer and Mathematical Sciences, 7(6) (2016) 302-307.

12. V.R.Kulli, General topological indices of circumcoronene series of benzenoid, International Research Journal of Pure Algebra, 7(5) (2017) 748-753.

13. V.R.Kulli, Computation of some Gourava indices of titania nanotubes, Interational Journal of Fuzzy Mathematical Archive, 12(2) (2017) 75-81.

14. V.R.Kulli, Computing Banhatti indices of networks, International Journal of Advances in Mathematics, 2018(1) (2018) 31-40.

15. V.R.Kulli, Some new fifth multiplicative Zagreb indices of PAMAM dendrimers, Journal of Global Research in Mathematics, 5(2) (2018) 82-86. 
16. V.R.Kulli, Multiplicative connectivity Banhatti indices of dendrimer nanostars, Journal of Chemistry and Chemical Sciences, 8(6) (2018) 964-973.

17. V.R.Kulli, Connectivity Revan indices of chemical structures in drugs, International Journal of Engineering Sciences and Research Technology, 7(5) (2018).

18. V.R.Kulli, On augmented reverse index and its polynomial of certain nanostar dendrimers, International Journal of Engineering Sciences and Research Technology, 7(8) (2018) 237-243.

19. V.R.Kulli, On two arithmetic-geometric Banhatti indices of certain dendrimer nanostars, International Journal of Fuzzy Mathematical Archive, 16(1) (2018) 7-12.

20. V.R.Kulli, Computation of arithmetic-geometric Revan indices of certain benzenoid systems, Journal of Global Research in Mathematical Archives, (2018).

21. V.R.Kulli, Computing two arithmetic-geometric reverse indices of certain networks, International Research Journal of Pure Algebra, (2018).

22. V.R.Kulli and M.H.Akhbari, Multiplicative atom bond connectivity and multiplicative geometric-arithmetic indices of dendrimer nanostars, Annals of Pure and Applied Mathematics, 16(2) (2018) 429-436.

23. V.R.Kulli, B.Chaluvaraju and H.S.Baregowda, $K$-Banhatti and $K$ hyper-Banhatti indices of windmill graphs, South East Asian J. of Math. and Math. Sci, 13(1) (2017) 11-18.

24. V.R.Kulli, Some topological indices of certain nanotubes, Journal of Computer and Mathematical Sciences, 8(1) (2017) 1-7.

25. V.R.Kulli, General topological indices of circumcoronene series of benzenoid, International Research Journal of Pure Algebra, 7(5)(2017) 748-753.

26. V.R.Kulli, Computing F-reverse index and F-reverse polynomial of certain networks, International Journal of Mathematical Archive, 9(8) (2018).

27. V.R Kulli, Edge version of $F$-index, general sum connectivity index of certain nanotubes, Annals of Pure and Applied Mathematics, 14(3) (2017) 449-455.

28. V.R.Kulli, General Zagreb polynomials and F-polynomial of certain nanostructures, International Journal of Mathematical Archive, 8(10) (2017) 103-109.

29. V.R.Kulli, $F$-index and reformulated Zagreb index of certain nanostructures, International Research Journal of Pure Algebra, 7(1) (2017) 489-495.

30. V.R.Kulli, Computing the F-ve-degree index and its polynomial of dominating oxide and regular triangulate oxide networks, International Journal of Fuzzy Mathematical Archive, 16(1) (2018) 1-6.

31. V.R.Kulli, Computation of F-reverse and modified reverse indices of some nanostructures, Annals of Pure and Applied Mathematics, 18(1) (2018) 37-43.

32. V.R.Kulli, B.Stone, S.Wang and B.Wei, Generalized multiplicative indices of polycyclic aromatic hydrocarbons and benzenoid systems, Z. Naturforsch, 72(6)a (2017) 573-576. 